\title{
A Study of Depiction of Clothing on Utagawa Kuniyoshi's One Hundred and Eight Heroes of the Popular Suikoden All Told
}

\author{
Wu Songlin ${ }^{1, a}, P e i \mathrm{Yu}^{2, \mathrm{~b}}$
}

\author{
${ }^{I}$ college of fashion and design, Donghua University, Shanghai, China \\ ${ }^{2}$ college of fashion and design, Donghua University, Shanghai, China \\ awusonglinsusln@qq.com \\ bppyy19991122@163.com
}

\begin{abstract}
This article examines Utagawa Kuniyoshi's study of Chinese painting and the relevance of the portrayal of the magnates to literature, and explores Utagawa Kuniyoshi's intention to represent the different identities of the magnates and their stylization as military generals. Secondly, he discusses the decorative and symbolic significance of the costumes and the aesthetic concepts of the Edo people as reflected in the works. Through the above examination, we will grasp Utagawa Kuniyoshi's creative thinking and intentions for the costume of the great warriors, and position the series in the history of Japanese art.
\end{abstract}

Keywords : Water Margin Painting, Costume Patterns, Chinese Interest, Literature and Painting

\section{歌川国芳《通俗水汻传豪杰百八人之一个》系列人物服 饰表现研究}

${\text { 乌阝 } \text { 松林 }^{1, \mathrm{a}} \text {, 裴育 }}^{2, \mathrm{~b}}$

\footnotetext{
1 东华大学服装与艺术设计学院, 上海, 中国

2 东华大学服装与艺术设计学院, 上海, 中国

${ }^{a}$ wusonglinsusln@qq.com

bpyy19991122@163.com
}

\section{摘要}

本文通过考察国芳对中国绘画的学习情况, 以及豪杰形象与文学作品之间的关联性, 探讨国芳对豪杰的不同 身份以及武将化造型的表现意图。其次针对豪杰服装的装饰性和象征意义及作品所反映的江户民众的审美观 念进行探讨。通过以上考察把握国芳对豪杰造型的创作思路和创作意图, 并对该系列在日本美术史上的历史 地位进行定位。

关键词：水吘传绘画；服饰纹样；中国趣味；文学与绘画

\section{1. 参考先行绘画}

歌川国芳是日本江户时代幕末活跃的绘师, 也是 歌川派三大巨匠之一。美术史上对其有“武者绘国芳”、 “水游传国芳” 两种评价, 前者多被论及, 后者却少 见相关研究。国芳在其画业生涯中陆续创作出水吘传
绘画多达十一个系列。1827 年由加贺屋出版的《通 俗水吘传豪杰百八人之一个》大判锦绘系列是国芳的 成名作, 对国芳的画业及其在武者绘界的地位有着重 要的历史意义。最终该系列共出版作品七十四幅, 被 称为国芳武者绘成功的原点 ${ }^{[1]}$ 。

《百八人之一个》大判锦绘系列中豪杰的造型取 
向从直观性来讲有参考中国先行绘画和小说原作人 物描写两种。从造型的内在性来讲, 还表现在通过豪 杰着装来体现人物身份地位和特定的作战面, 而豪杰 华丽的服装刻画也与塑造人物形象及性格特征、彰显 豪杰作战的威猛、暗示豪杰的身份地位以及江户时代 的审美追求紧密相关。本文旨在通过以上角度的逐一 分析, 考察《百八人之一个》豪杰的造型取向, 探讨 国芳对《水吘传》小说原作中豪杰造型的创作意图及 其意义。

先行研究对国芳参考过的中国水汻传绘画主要 提及了陈洪绶《水吘叶子》和陆谦《天罡地繁图》两 类作品, 但没有考证引用关系中陆谦对陈洪绶作品的 借鉴情况, 对先行绘画内容的考察也缺乏全面性。本 节将国芳对以上两作品的借鉴情况进行系统分析, 并 于此基础上提出新的图像影响关系。

\section{1 陈洪绶《水做叶子》}

《水吘叶子》(1625 年) 是中国明末清初的文人 画家陈洪绶以白描形式将水湤豪杰刻在酒牌上的绣 像作品, 全作共刻画豪杰四十幅, 附题赞。该作品构 建了水吘传绘画的基础, 对此后的中国乃至日本水吘 传绘画均影响极大, 豪杰的造型表现对《百八人之一 个》起到直接性的影响 ${ }^{[21]}$ 。

首先, 从豪杰的动势来看, 陈洪绶善于吸取戏曲 人物造型元素, 表现豪杰背影或侧四分之三背影角度 的造型 ${ }^{[22]}$, 如史进夸张扭曲的上半身造型。而国芳对 豪杰背影形态的刻画则结合了歌舞伎文化, 如张青的 动势参考歌舞伎 “见得” 的姿态。可见国芳在学习陈 洪绶对戏曲元素的借鉴的同时, 结合日本传统文化进 行表现。其次, 从豪杰的造型来看, 两幅作品对朱全 的刻画虽然出自不同故事场景, 但从二者视线的方向, 上半身倾斜角度, 头巾的造型等方面能看出国芳吸收 陈洪绶表现的痕迹。再有, 朱武的发型、动态、服装 及降服妖魔的场景描绘均参考《水吘叶子 公孙胜》 的表现特征。凌振的铠甲装束和人物站姿及侧身站立 角度参考《水吘叶子 索超》的造型表现。

\section{2. 陆谦《天罡地繁图》}

《天罡地繁图》人物群像图为 1805 年曲亭马琴 在编著《新编水汻画传》时, 绘师担当葛饰北斋命其 弟子临摹陆谦之作, 现藏于日本早稻田大学。同内容 另有一版本名为《百八人像赞临本》, 前者用单纯的 白描表现, 后者增加了阴影效果。

先行研究主要论述了国芳对《天罡地第图》中豪 杰造型、用线方面的学习 ${ }^{[20]}$ 。然而从陆谦对豪杰的造 型表现中亦能看出其直接参考《水吘叶子》的痕迹。 如鲁智深面部、衣禇和禅杖的刻画。朱全抱小衙内的 作画主题和豪杰的服装造型。史进的头部朝向、腿部 和臂部的弯曲幅度几乎照搬陈洪绶的刻画, 只是将 《水㴾叶子史进》上半身的正反面进行了对调。这
样看来, 国芳所参考陆谦的豪杰造型刻画亦有间接吸 收《水吘叶子》的可能性, 比如《百八人之一个 朱 武》与《天罡地繁图 公孙胜》、《水吘叶子 朱武》三 幅作品中豪杰造型和场景刻画有明显的近似性, 但从 朱武的着装、赤脚的造型、手中所持的古剑、宝壸以 及妖怪的刻画内容来看, 国芳与陆谦的造型表现更为 接近。再有, 《百八人之一个 马麟》中豪杰治服怪兽 的作画灵感亦出自《天罡地整图 谢珍》一图, 由以 上可知国芳对陆谦造型的直接引用情况。

\section{1 结合原作描写}

《百八人之一个》豪杰的造型取向除了引用先行 绘画以外, 亦有根据绘师在参考小说原作的描写基础 上加入自身理解而创作的。国芳对小说原作描写的参 考大体有人物面部特征, 服装款式、色彩及配饰等方 面。国芳将以上小说特定情境中的豪杰造型描写如实 地还原于画面中。除此之外, 豪杰造型亦有同时参考 原作多个场景中的形象描写。

\section{3. 反映人物身份}

\section{1 穿戴方式}

《百八人之一个》豪杰披战袍的不同方式暗示了 人物身份或阶层的不同。作品中豪杰将袍服衣袖脱去 并系在腰间, 即上身裸露式穿戴的豪杰共十位, 该穿 戴方式一般用以表现豪杰入伙之前、或出身阶级低、 再或座次排名靠后的人物形象。豪杰全身披战袍的造 型共十六位，一般用来表现出身官僚地主阶级、或入 伙之后、亦或座次排名靠前的豪杰形象。出身官僚阶 级的豪杰。

另外，身披战袍的服装形制分为包肚制和袍甲制， 将身着两种形制的豪杰进行横向比较可知, 着袍甲制 豪杰的座次排名要比包肚制的 (除了入伙梁山以前的 杨志以外) 靠前。尤其是刻画入伙后的豪杰时多采用 袍甲制装束, 这也反映了绘师注重表现武将作战时服 装的仪式感, 突出武者绘题材的属性。

\section{2 服饰色彩}

身着青色袍服的豪杰中, 描绘入伙后的人物有杨 林、汤隆、宋万、吴用。描绘入伙前的人物有史进、 朱武、段景住、燕青、卢俊义、林冲、张清、杨雄。 将两组豪杰对比可知, 入伙后的豪杰 (除吴用) 较入 伙前的豪杰 (除段景住) 相比座次排名靠后。而吴用 所穿青色道袍反映了明代常服的特点 ${ }^{[7]}$ 。段景住虽排 位靠后, 但画面描绘的故事内容发生在其意决入伙之 后。身着绿色袍服的豪杰中, 表现入伙后的人物有时 迁、朱贵、孔明、孔亮、穆弘、杜迁、萧让。表现入 伙前的人物有石秀、阮小五。两组豪杰相比, 入伙前 的人物座次排名也均相对靠前。入伙后的人物除萧让 和穆弘以外, 座次排名均较为靠后。其中萧让为文人 
出身，穆弘的身份特征已反映在其穿戴方式上。身着 红色袍服的豪杰有王英、杨志、武松、王定六、刘唐。 除王定六以外, 豪杰的座次排名均列居前位, 并且取 材于人物入伙后的故事背景所作。

综上所述, 国芳通过豪杰袍服的穿戴方式和甲䡒 佩戴情况来反应人物身份及座次的先后。袍服用色总 体遵照明代服制的等级规范, 穿着同色袍服的豪杰又 根据入伙前后的不同反映了座次的先后, 可以看出国 芳对豪杰入伙前后身份转变的作画意识, 即豪杰通过 落草为寇可晋升为高级身份的理念。

\section{4. 应对作战安排}

《百八人之一个》豪杰造型参考小说描述的内容 倾向于选择人物战斗时华丽的铠甲装扮, 因此作品中 袍甲制装束便成为豪杰的主要服饰。甚至对于原作中 未出现甲贯造型描写的豪杰, 国芳也有意识的为人物 增添甲胄装束, 用以应对豪杰的作战安排, 突出人物 威猛的战斗姿态和气势。其次, 国芳对豪杰造型的表 达也根据具体的作战或行动情况而定。

\section{5. 《百八人之一个》服饰的装饰性}

《百八人之一个》豪杰服饰呈现出华丽的装饰效 果, 战袍、甲䡒、包肚、行缠、甚至袍服与铠甲里祄、 包边处均反映出很强的装饰意味, 尤其是甲胄呈现出 的装饰性已远大于实用性。本节从豪杰服装纹样装饰 性的视角出发, 对装饰图案的类别和构成形式进行归 类与分析，探讨豪杰服装纹样的造型方式和象征意义。

\section{1 装饰纹样}

《百八人之一个》豪杰服装的植物纹样主要有花 卉纹和瓜果纹两种。唐花、唐草纹、瓜果纹多用以构 成单独纹样或适合纹样。其中单独纹样常装饰于豪杰 衣袍、裙身、护颈等部位, 多以散点式排列图案。适 合纹样中常见的是团花纹, 穿着大团花纹服饰的豪杰。 连续纹样的豪杰服装上多表现卷草纹, 并以满地图案 的形式作主花型出现, 给人华丽的印象。

动物纹样主要装饰在豪杰的袍身、捍腰、包肚、 胸甲片、战补子, 或者下身的裤、裙、铠甲部位, 题 材以吉祥纹样为主, 且猛兽类图案居多, 如龙纹、凤 纹、白铎纹、麒麟纹等。动物纹样用作装饰豪杰袍身 或铠甲的主花型时, 常搭配植物纹作副花型一同表现。

豪杰服饰纹样中出现的几何纹样有回形纹、雷纹、 流云纹、水波纹等。几何纹在豪杰服饰中运用面积较 小, 多以二方连续的形式作边缘纹样使用。几何纹多 装饰于豪杰的捍腰边缘、袍服下摆或袖口、包边等服 装边缘部位。也常用作豪杰服装的暗花或里祄装饰, 用作服装暗花装饰。

\section{2 装饰纹样的象征意义}

豪杰服饰的装饰性与人物形象、性格特征的塑造 有密切的联系。另外, 豪杰服装纹样多借用动物图案 的象征意义来增添人物作战的勇猛气势。也有通过服 饰纹样来祄托豪杰作战神力的, 借用日本神话传说中 的人物作战特征来表现水汻豪杰降服妖术的场景等。 豪杰的服饰纹样还反映了人物身份地位的不同。从装 饰纹样的内容来看, 出身军官、押狱或其他低级官职 的豪杰服装多用有职纹样。还有用纹样的引申含义来 象征豪杰高贵身份，或是体现豪杰人物身份关系的。

\section{3 迎合时代审美}

首先，国芳对江户时代的工艺品、服饰中常见的 装饰纹样进行借鉴，以迎合日本庶民的审美习惯。其 次, 豪杰服装纹样的装饰表现亦注重迎合武士阶层的 审美观, 常见对有职纹样的参考元素。另外, 《百八 人之一个》的审美性也表现在绘师对日本绘手本的利 用。国芳对豪杰服装纹样的创作从日本民众的审美视 角出发, 意在表现日本人理解的中国味道。

\section{6. 结论}

《百八人之一个》中豪杰的造型取向除了借鉴先 行绘画、结合小说原作描写进行创作以外, 绘师还有 意识的运用豪杰服装穿戴方式和色彩来暗示人物的 身份地位。在服装表现上，国芳为迎合豪杰作战安排 将服装造型武士化, 并且利用服饰纹样来反映豪杰的 身份等级区分和入伙前后形象的转变。服装纹样参考 中日传统纹样造型, 尤其是日本人所熟悉的中国元素, 反映江户时代民众的审美取向, 这主要取决于浮世绘 版画的商业性特点，即迎合民众的购买心理而创作。 国芳在学习中日先行绘画的同时, 开创了自身对水汻 传武者绘表现的新境界。

\section{REFERENCES}

[1]Suzuki,S.,(1992)Utagawa Kuniyoshi[M], Tokyo: Heibonsha.

[2]Suzuki,S.,(1985)Utagawa Kuniyoshi-Colorful Kibana Painting [M], Tokyo: Hirafunsha.

[3]Toshio,T.,(2006)Mizuhara and the Japanese [M], Tokyo: Chikuma Bunko, November.

[4] (Ming) Shi,N.A.,(2008)Water Margin [M], Changsha: Yuelu Shusha.

[5]Sha,X.N.,(2006)The Water Margin Dictionary [M], Wuhan: Chongwen Shuji.

[6] Zhou,F. and Gao,C.M,(1996)A Dictionary of Chinese Clothing and Costumes[M],Shanghai: Shanghai Dictionary Publishing House.

[7] Zhang,T.Y. et al. and Yang,J.L., editors,(2014) 
"Ming History-Mianzhu Zhi" [M],Beijing:China Book Bureau.

[8]Zhou,B.Q.,(2008)Ancient and Modern Book Integration.Etiquette Dictionary-Clothing Department [M], Beijing: China Drama Publishing House.

[9]Huang,H.,(2011)"Chinese Costume System Costumes in All Ages" [M], Jiangxi: Jiangxi Art Publishing House.

[10]Zhou,X.B.,(1984)The History of Ancient Chinese Costumes [M], Beijing: China Drama Publishing House.

[11]Liu,Y.H.,(1995)Ancient Chinese Military Costumes $[\mathrm{M}]$, Shanghai: Shanghai Ancient Books Publishing House.

[12]Chen,D.W., (2009)Pictorial Description of Chinese Armor Through the Ages [M], Shanghai: Shanghai Century Publishing House.

[13]Hayasaka Y.,(2000)Nihon no Chugoku no Bunmeisho[M],Osaka: Visual Design Institute, January.

[14]Sasaki,M.(2011)"Kokubata ga modoshita mizuho no hazama" [J], The University of Tokyo Conexion (12): "Genuine Fake No Hazama".

[15]Sato,G., (1981)"Kokusai Suizuhari-den and the
Seven Edited Drafts" [J], Kokusai and Kokusai Literature (691).

[16]Nakayama,S.T.,(2015)"Kakegawa Kuniyoshi Studies - Cultural Interaction in the 19th Century" [J], Kobe City Museum Research Bulletin (31) no.

[17]Zhou,P.,(2011)《Utagawa Kuniyoshi Water Margin Painting [J], Art Research (11), Art Research Center of Ritsumeikan University.

[18]Shi.Z.,(2003)"Chen Hongshou Water Margin Character Painting and the Influence on Japanese Water Margin Painting" [J], art and design.

[19]Shi.Z.,(2013) "The Water Margin Paintings of Ukiyo-e Master Kokuyo Kogawa" [J], Foreign Art.

[20]Nakayama,S.T., (2015)"Ukiyo-e master Niimiru no Utilization of the painting handbook" [J], Kobe City Museum Research Chronicle (31) No.

[21]Waseda University Performing Arts Musum The database, http://www.enpaku.waseda.ac.jp:/db/.

[22]Chen,L.L.,(1959)n < Shuizu Hu Ye Zi> [M], Jiangsu: Jiangsu Arts and Crafts Research Office.

[23]Wei,B., (2011)"Chinese Arms and Armor Pictorial Dictionary" [M], Beijing: China Book Bureau.

[24]Zhao,L.S., (2007)Ancient Chinese Costume Atlas [M], Kunming: Yunnan People's Publishing House. 